\title{
Networks of Clusters: A Governance Perspective
}

\author{
Elke Schüßler \\ Freie Universität Berlin \\ School of Business and Economics \\ Department of Management \\ Boltzmannstr. 20 \\ D-14195 Berlin, Germany \\ Phone: +49 3083856807 \\ Fax: +493083856808 \\ e-Mail: Elke.Schuessler@fu-berlin.de \\ Carolin Decker \\ WHU - Otto Beisheim School of Management \\ Burgplatz 2 \\ D-56179 Vallendar, Germany \\ Phone: +49 2616509333 \\ Fax: +49 2616509339 \\ e-Mail: Carolin.Decker@whu.edu \\ Frank Lerch \\ Helmut-Schmidt-University Hamburg \\ Department of Economics and Social Science \\ Holstenhofweg 85 \\ D-22043 Hamburg, Germany \\ Phone: +49 4065412080 \\ Fax: +49 4065412087 \\ e-Mail: frank.lerch@hsu-hh.de
}




\title{
Networks of Clusters: A Governance Perspective
}

\begin{abstract}
This paper aims to further our emerging knowledge on the external linkages of clusters. We adopt a network governance perspective and study connected clusters as goal-directed, multilevel whole networks that we denote as 'cluster networks'. Based on an analysis of four empirical cases varying in regional scope, age, and industry context, we identify two governance forms: internally governed cluster networks are formed to establish ties among cluster representative organizations to share knowledge and pool resources on selected activities; externally governed cluster networks are formed to systematically develop crosscluster ties and competences on and across levels and are brokered by a central inter-cluster administrative organization and several decentralized lead organizations. Our findings show that cluster connectivity can go beyond organization-based pipelines and personal relationships to include clusters as governed entities, albeit with different intensities regarding the brokerage of ties on lower levels.
\end{abstract}

Keywords: regional clusters, cluster collaboration, cluster network, cluster connectivity, whole networks, governance, global pipelines, territorial innovation systems

Acknowledgements: We gratefully acknowledge the insightful comments received from participants at research seminars at Freie Universität Berlin and Tilburg University and from conference participants at the European Group for Organizational Studies Colloquium (2011) and the Workshop on Organization Studies of the German Association for Business Research (2012). We are particularly indebted for their detailed feedback on earlier drafts to Stephan Kaiser, Leon Oerlemans, Christina Günther, Vincent Mangematin, and Jörg Sydow. Joachim Thiel helped us in refining the title. The editor Mark Lorenzen and three anonymous reviewers have contributed significantly towards improving the paper through their valuable developmental advice. All remaining errors are ours.

JEL: O18, D85, L14 


\section{Introduction}

Regional clusters, defined as "geographic concentrations of interconnected companies, specialized suppliers, service providers, firms in related industries, and associated industries in a particular field that compete but also co-operate” (Porter, 1998: 197), have attracted researchers' interest for decades (e.g. Bresnahan et al., 2001; Hoover, 1937; Marshall, 1890; Scott, 2002; Staber, 1997). In efforts to specify the functioning of this highly contested concept (Martin and Sunley, 2003), research has paid attention to the actual networks forming within (Visser, 2009; Visser and Boschma, 2004), but also between different clusters (Asheim and Isaksen, 2002; Boschma, 2005; Humphrey and Schmitz, 2002; Lorenzen and Mudambi, 2012). Such often non-local, external linkages of clusters are established by gatekeepers (Rychen and Zimmermann, 2008), technical, entrepreneurial or transnational communities (Saxenian, 2002, 2006; Saxenian and Hsu, 2001), global pipelines (Bathelt et al., 2004), or temporary encounters (Maskell et al., 2006).

Although external linkages are recognized as crucial for developing and maintaining the innovativeness of clusters (Ter Wal and Boschma, 2011), only few studies examine the idiosyncratic, multi-level ties established between clusters to achieve certain goals (e.g. Engel and del-Palacio, 2011). Such an analysis is necessary to understand how clusteradministrative bodies or other organizations within clusters can support the development of shared goals and institutionalized mechanisms of problem-solving, the accessing of markets and funding sources, or the transfer of knowledge in the complex web of centralized and decentralized, strong and weak, organization- and person-based ties characterizing crosscluster linkages (Bathelt et al. 2004; Gilding, 2008; Lorenzen and Mudambi, 2012; Visser and Atzema, 2008). We therefore propose to study connected clusters as multi-level whole networks (Provan et al., 2007) that require governance to achieve common goals (Provan and Kenis, 2008). A governance perspective allows us to shed light on a variety of goals and 
forms of cluster connectivity by considering the cluster and the inter-cluster levels as additional levels of analysis on which linkages may be formed. We analyze four empirical cases of cluster collaboration varying in age, size, regional scope, and industry to understand what governance approaches are used to ensure goal alignment on and across cluster and inter-cluster levels.

Our contributions are twofold. First, we identify internally and externally governed cluster networks as different forms of governing cluster collaboration. Whereas organizationbased pipelines (Gupta and Govindarajan, 2000; Mudambi and Swift, 2012) and personbased relationships across clusters (Saxenian, 2002, 2006) are more or less emergent from a cluster perspective, cluster networks are designed by and systematically involve cluster-level actors. These can be private organizations acting on behalf of clusters, cluster-administrative organizations (CAOs), or inter-CAOs. Second, we discuss the impact of structural and relational factors on the formation of cluster networks to elaborate on the rationales behind different governance forms. Especially the absence of strong global pipelines can be a motivation for forming cluster networks, and externally governed cluster networks are more likely to occur in neighboring rather than globally distant regions.

We proceed as follows. First, we outline levels and factors pertaining to the governance of cluster collaboration. Second, we elaborate on our cases, data sources and analysis. Third, based on our findings, we specify and compare two governance forms and outline the implications of our results.

\section{Governing Cluster Collaboration}

\subsection{Connected Clusters as Goal-Directed, Multi-Level Whole Networks}

Existing research on cluster connectivity distinguishes person-based and organization-based linkages (Lorenzen and Mudambi, 2012). Person-based linkages result from transregional or 
transnational entrepreneurs promoting the transfer of knowledge from one cluster to another (Saxenian, 2002, 2006). Organization-based linkages are typically formed by multi-national enterprises (MNEs) that establish relationships with subsidiaries or alliance partners and gatekeepers in other clusters to nurture the transfer of proprietary knowledge (Cheung et al., 2011; Giblin, 2011; Vapola, 2011). Although a limited number of actors within a cluster benefits from such ties, their utility for entire clusters is unclear (Henn, 2012).

We conceive of cross-cluster ties as goal-directed rather than serendipitous (Kilduff and Tsai, 2003), based on “conscious efforts to build coordination” (Provan and Kenis, 2008: 231) across clusters. Although serendipitous interactions may also occur, clusters cooperate for a specific cluster-related purpose such as enhancing participants' innovative abilities, attracting public funding, or strengthening regional economic development. They are frequently supported by national or regional policies (Asheim and Coenen, 2005; Dohse, 2007). This goal-directedness requires governance "to ensure that participants engage in collective and mutually supportive action, that conflict is addressed, and that network resources are acquired and utilized efficiently and effectively” (Provan and Kenis, 2008: 231).

Building on and extending Provan and Kenis' (2008) network governance approach, we define cluster networks as multi-level whole networks that, compared to networks, additionally comprise the levels of clusters and inter-cluster linkages. More precisely, actors participating in cluster networks are network partners residing in different clusters that, in turn, are embedded in networks among clusters. A shared institutional context enables learning within and across clusters. It guides the transfer of knowledge, project guidelines, and joint goals from organizational to network, cluster, and inter-cluster levels or directly from the organizational to the inter-cluster level - or vice versa (Bathelt et al., 2004; Bunker Whittington et al., 2009; Gilding, 2008; Menzel and Fornahl, 2010). 
Governance can be categorized along the dimensions of brokerage and leadership (Provan and Kenis, 2008). On the cluster level, hub firms (Jarillo, 1988) can have orchestrating functions. Alternatively, similar to network administrative organizations (Human and Provan, 2000), CAOs are established as external cluster leaders (Sydow et al., 2011). They monitor goal-directed activities on the inter-cluster level and endow an interCAO with resources, power, and legitimacy to coordinate decisions and collective actions so as to establish a centralized, external lead organization. Organizations or individuals residing within clusters can act as brokers of ties to other clusters on and across different levels to bridge “structural holes” (Burt, 1992).

The degree of centralization depends on the number of specialized investments in cluster collaboration. Generally, the leaders of cluster networks are responsible on behalf of their clusters for "making things happen" on the inter-cluster level (Huxham and Vangen, 2005). Such leadership involves intense brokering of ties on and to 'lower' levels if only a limited number of actors have sufficient power and resources to take a leading role. If power and resources are symmetrically distributed, network actors refrain from a centralized brokerage (Provan and Kenis, 2008).

The formalization and institutionalization of inter-cluster leadership depends on the extent of public funding and on financing models. Formal institutions need to be established if national or supra-national innovation policies support cross-cluster linkages (Asheim and Coenen, 2006; Dohse, 2000). Further contingencies reflect the goals and multi-level character of cluster networks and influence their governance (Provan and Kenis, 2008).

\subsection{Relational and Structural Contingencies of Cluster Networks}

Goal consensus requires agreement on network-level content and process-related goals, but the goals of network members need not be similar (Provan and Kenis, 2008). Brokers and leaders in cluster networks define common goals and mobilize for goal 
alignment (Huxham and Vangen, 2000). Goal consensus is also influenced by the regional scope of a cluster network. For instance, supra-national initiatives such as those pursued by the European Union nurture cluster collaboration within clearly defined geographic and political boundaries and align goals to some extent through funding incentives (Kuhlmann and Edler, 2003). Cluster networks can also comprise inter-continental relationships (Bathelt et al., 2004; Engel and del-Palacio, 2011; Gilding, 2008) to manufacture cognitive, cultural and temporary proximity (Boschma, 2005; Bunker Whittington et al., 2009). Goal consensus may be moderate or high on the inter-cluster level, but much lower on the level of organizations residing within clusters. If long-term cluster network sustainability is to be achieved, the governance of cluster networks should involve at least a subset of member organizations on different levels (Provan and Kenis, 2008).

Trust is related to governance (Provan and Kenis, 2008) and depends on the intensities and durations of the linkages between clusters. Ties may be recurring or sporadic (Granovetter, 1973). While trust density may remain low in cluster networks overall, it can be high in selected inter-organizational networks across clusters. Trust-based ties among governing actors on the inter-cluster level suffice to make the cooperation effective. Generally, the nature of cross-cluster ties is expected to correlate with the nature of local ties (Lorenzen and Mudambi, 2010). If clusters lack prominent lead organizations and instead have trust-based personal relations, shared governance on the inter-cluster level is likely.

Cluster networks comprise ties between various numbers of participants on different levels (He and Fallah, 2011). On the inter-cluster level, collaboration is unlikely to exceed a small number of clusters, but each cluster typically comprises many organizations residing within them whose networking needs to be facilitated by adequate governance structures. The higher the number of participants on different levels, the higher the need is for a central entity that coordinates their needs (Provan and Kenis, 2008). 
Cluster networks require cluster and inter-cluster level competencies that depend on the nature of the tasks that are performed and the demands and needs that are faced by the participants (Provan and Kenis, 2008). If innovation is the main goal, a competence must be developed that ensures participants' access to complementary knowledge located in the collaborating clusters and its transfer to the place where it is needed (Herrmann et al., 2012). The need for cluster and inter-cluster level competences also varies depending on the industry in which cluster networks are established. Industries can be supplier-dominated and production-intensive, where existing knowledge is exploited to nurture incremental innovation that benefits from interactive learning with customers and suppliers, such as the automotive industry. Science-based industries such as the biotechnology industry aim at radical innovation often pursued collaboratively by companies and research organizations (Asheim and Coenen, 2005; Pavitt, 1984). Governance depends on the kind of knowledge that is exchanged and the type of innovation to be pursued in an industry (Lorenzen and Mudambi, 2012). While formal governance is beneficial in transferring proprietary knowledge among selected actors, radical innovation requires a governance approach that allows broader spillovers across clusters (Bunker Whittington et al., 2009).

\section{Case Analysis}

Since our knowledge about cluster networks is limited, we have chosen a multiple-case design that allows us to uncover different facets of this phenomenon (Yin, 2009). We have selected four cases of collaborating clusters differing in age, size, regional scope, and industry so as to identify and explain commonalities and differences in their governance. We have identified these factors as relevant for the governance of cluster networks on the basis of theoretical considerations. The knowledge base of an industry, for instance, influences the 
formality of governance forms; size affects the degree of centralized brokerage; regional scope has an effect on goal consensus and the extent to which governance is shared.

The first case is the Automotive Cluster East Germany (ACOD), a national collaboration among five state-based automotive networks and cluster initiatives initiated in 2004 and supported by national public funding. The second case is Germany goes 3D that emerged in 2010, a national collaboration between the three leading German pop music industry clusters in Berlin, Cologne, and Hamburg. The third case is the transcontinental TriCluster Berlin-Tucson-Ottawa Alliance between the photonics clusters in BerlinBrandenburg, Tucson (Arizona), and Ottawa (Ontario), initiated in 2004. The fourth case is the ScanBalt BioRegion, a transnational network of biotechnology clusters and organizations from eleven countries in the Baltic Sea Region initiated in 2001.

We conducted five to six interviews per case between 2007-2012, focusing on informants from different organizations who had been involved - continuously or at key points in time - in governing cross-cluster linkages either as cluster leaders or as representatives of the inter-CAOs. Typically, we have addressed our interviewees in two roles: as representatives of a cluster with respective interests, and as experts in the goals and governance of the respective cluster network. We also interviewed one European Commission official involved in fostering cluster collaboration in the photonics industry to gain insights into policy issues. Altogether, we conducted 29 semi-structured interviews (see Table 1), which took 30 minutes on average.

--- Insert Table 1 about here ---

The interviews covered five broad areas: (1) general information about each initiative, such as starting-point and evolution, initiators and members, expectations and goals, (2) interaction, such as opportunities for communication and cooperation on and across levels, rules, guidelines, and practices for cluster collaboration, (3) governance, such as formal and 
informal control mechanisms, conflicts, and mechanisms for achieving goal consensus and conflict resolution, (4) background information and interviewees' personal assessment, such as specific purpose of the collaboration, key communication and cooperation partners, type of knowledge to be transferred, time, efforts and money to be invested by the partners, and (5) context, such as competition, territorial innovation policies (including public funding), and regulative and legislative pressures. If the interviewees agreed, the interviews were digitally recorded, transcribed and coded to categorize the collected data. For triangulation purposes, we analyzed a broad range of documents (e.g. strategy papers, newsletters, roadmaps, and reports) as background information, and, where possible, studied the initiatives' websites for additional material. Attending meetings and workshops gave us further cross-validation opportunities.

\section{--- Insert Table 2 about here ---}

As a first step of analysis, we wrote up brief histories of the development of each case before coding for our core theoretical constructs in more depth, which are outlined in Table 2. The constructs are useful because they reflect the goal-directedness and multi-level character of cluster networks, as well as the different bodies involved in governance and their interactions. We have thus engaged in a largely deductive coding process based on theoretically derived dimensions. At least two authors analyzed each of our cases in depth, so that we could compare our impressions and gain shared insights into all of our cases. Once we had roughly coded and discussed the governance structures and contingencies for each case, we compared and contrasted our findings across cases. It quickly became obvious that ACOD and ScanBalt were similar regarding their goals, complexity and formality, whereas the Tri-Cluster Alliance and Germany 3D were comparable regarding their informal and hollow nature. Comparing the similarities and differences within each of these pairs helped us to develop and refine our typology. For instance, even though Tri-Cluster and 3D differ substantially 
regarding their regional scope and industry, they nonetheless pursue similar goals such as the sharing of limited resources and gaining political visibility, which has affected the governance form chosen.

\section{Findings}

\subsection{Case Histories}

\subsubsection{ACOD}

ACOD, founded in 2004 on the initiative of the original equipment manufacturers (OEMs), is engaged in the automobile industry in East Germany. It comprises five regional state initiatives (AutoMobilZulieferer Sachsen, automotive Berlin-Brandenburg e.V., automotive Mecklenburg-Vorpommern e.V., automotive Thüringen e.V., and MAHREG Automotive/Sachsen-Anhalt Automotive e.V.) and about 370 organizations (OEMs, suppliers and service providers, research institutes, associations, and other institutions that are related to the automotive industry). ACOD's goal is the development of the automobile industry in East Germany, which mainly comprises small and medium-sized enterprises (SMEs) that aim to cooperate with the OEMs but do not fully match the requirements of these globally operating companies:

"We need to organize for a higher added value and innovation performance in the supply chain, and we need to increase the R\&D performance of the local supplier companies. In particular, we are supporting the small and medium sized companies to professionalize and to climb the tier-hierarchy.” (ACOD interview)

ACOD fosters the national and international interest in the East German automotive industry by providing platforms (e.g. International Motor Show Cars, the Hanover International Motor Show Commercial Vehicles, or Subcontracting Fair “Z” in Leipzig). To promote East Germany as a European center for high-tech products for the automotive sector, it provides contacts to influential political institutions on a national and a state level. 


\subsubsection{Germany goes 3D}

Founded in 2010, Germany goes 3D connects the three main popular music regions in Germany: Berlin, Hamburg, and Cologne. It is represented by Cologne-based c/o pop GmbH, the Berlin Music Commission, and the Hamburg-based Reeperbahn Festival GbR and IHM (Interessengemeinschaft Hamburger Musikwirtschaft). The collaboration has been established as a working group in which members share selected interests and topics that permit the pursuit of joint aims such as resource sharing and gaining visibility among national politicians despite otherwise fierce regional competition. Salient activities are, for instance, joint presentations at trade fairs abroad and the 3D Receptions during the Berlin Music Week, the Reeperbahn Festival in Hamburg, and the c/o pop in Cologne. These receptions have the advantage that international partners can meet representatives of each partnering region during each event rather than having to choose between one of the locations.

\subsubsection{The Tri-Cluster Berlin-Tucson-Ottawa Alliance}

The Tri-Cluster Alliance, formed in 2004, is an international collaboration of three clusters in the photonics industry. It aims to facilitate market access, intensify communication, and increase knowledge about the competences of the different firms residing in the respective clusters in order to, for example, support the search for suppliers for specific goods and pool resources where possible. A further aim is to increase the visibility of the value of the photonics industry vis-à-vis policy makers and customers. The collaboration started with the organization of a joint Tri-Cluster breakfast at the Photonics West trade fair in San Jose and has been followed up by several mutual visits. The Tri-Cluster breakfast has taken place regularly, alternating between the Photonics West and the "LASER World of Photonics" in Munich until 2011. It is currently being debated whether another breakfast will take place in 2013, so that the future of this cluster network is unclear. 


\subsubsection{ScanBalt BioRegion}

ScanBalt is a meta-region in life sciences around the Baltic Sea that includes Denmark, Estonia, Finland, Iceland, Latvia, Lithuania, Norway, Poland, Sweden, the northern part of Germany, and the north-western part of Russia. It currently comprises about 4,000 organizations (2,543 life science or life science related companies, 1,012 academic institutes and institutions, 238 hospitals and clinics, and 112 investors). The central goal of ScanBalt is to generate synergies and ensure the optimal exploitation of joint resources in the Baltic Sea region so as to achieve scale in global competition:

"We know that the universities in the Baltic States are not top rated, but in every university there are several groups that lead the world in their fields. So, why not go together and network so that the ScanBalt BioRegion can become critical and visible." (ScanBalt interview)

After initial collaborative efforts in 2001, in June 2004 a not-for-profit membership association was established. In 2006, ScanBalt suggested the foundation of a Baltic Sea Fund for Innovation, Research and Education that became a flagship project in the EU Baltic Sea Region Strategy.

\subsection{Comparing Cluster Networks}

\subsubsection{Governance Structures}

The governance of ACOD and ScanBalt is formal, complex, and brokered to a high extent. Both initiatives have founded legal entities that act as external lead organizations. At ACOD, the central executive body is the Board of Directors, composed of members of the interregional association (ACOD e.V.) that defines the basic cluster development processes. Its members - among them at least one representative of a state initiative - maintain key contacts on national, international, and regional levels and have to consider the special characteristics of each state initiative. Leadership is rotating, i.e. the chairman's role changes regularly among member organizations. The association ACOD e.V. has statutes that 
delineate the basic lines of collaboration. It is the shareholder of ACOD GmbH, a limited liability company that executes operational activities and constitutes the inter-cluster administrative office. ACOD GmbH acts as a broker of information between the competence networks, the state initiatives and the organizations residing within them, and representatives from the local political realm:

“(...) we have the association, and there is the member assembly, which is the formal way. Once a month we have a meeting with the state initiatives about activities and outcomes that are pertinent. The other contacts focus on events and activities and are bilateral. But in general, we have one meeting per month with the state initiatives and two member assemblies and six board meetings per year.” (ACOD interview)

ACOD GmbH initiates and manages activities on the inter-cluster level such as workshops, the ACOD conference, the presence of ACOD at trade fairs, and various competence networks that cover a wide range of expertise:

"These competence networks are governed by one or two persons who do not come from the central administrative office but are representatives of research institutes or companies and pursue their own interests with a topic.” (ACOD interview)

The five state initiatives are directly connected to the association ACOD e.V. via the Cluster Hub, a coordination platform. Its task is to align the goals and activities of the state initiatives that are responsible for supplier development in their respective regions and to pursue "a constructive dialogue without segregating conflict” (ACOD interview). The OEMs and the state initiatives have strong voices at the inter-cluster level. When it comes to specific projects such as the development of new technologies, individual research organizations or companies take the lead in organizing the project activities. There is a clear separation of competences between the cluster and the inter-cluster level, because the state initiatives adopt different approaches and opportunities to support their members:

"Activities across states are the ACOD's task, we are more likely to focus on the states." (ACOD interview, representative of a state initiative) 
However, competences that are developed on the state level, such as the ability to cooperate with regional clusters abroad, can be transferred into ACOD so that other participants may benefit.

ACOD e.V. draws its funding from membership fees. Paying members are the OEMs with plants in East Germany, a handful of systems suppliers, and influential research institutes. It is also co-financed by public funds, but these are due to decrease over the next years. Funding differs among the state initiatives that benefit from ACOD as a unified network, in that it helps them to apply for national funding:

"As a platform we have the best conditions to raise funds from the Federal Ministry of Economics and Technology.” (ACOD interview)

ScanBalt has founded a non-profit organization with a defined membership structure, an Executive Committee with a Chair, General Secretary and a Secretariat, while formal Statutes and Standing Orders are approved and adopted by a General Assembly. The central network broker, the one-person Secretariat based in Copenhagen supported by four liaison offices Copenhagen (Denmark), Tartu (Estonia), Gdansk (Poland), and Groningen (Netherlands) has mainly coordinative functions such as initiating EU funding applications or distributing information both within the macro region and between it and the EU. On an operational level, leadership within ScanBalt is more dispersed and based on projects. Despite the establishment of a central governing body, which became necessary due to an EU-funded project, the collaboration has retained a highly decentralized structure:

"It was very important for us to stress the bottom-up nature, since you need to have the regions take ownership of such a thing as ScanBalt Bioregion because you cannot sit at the top and expect people to participate in anything and be responsible to a centralized organization; that would be hopeless. The second point is that money cannot cross borders. This means you need to have activities placed out regionally and to have regions themselves do things but referring to an overall strategy, vision and mission.” (ScanBalt interview)

Both ScanBalt and ACOD combine a centralized external broker responsible for distributing information, developing a shared strategy and vision, providing an interface for policymakers, and coordinating activities with decentralized internal lead organizations 
representing the different member clusters or interorganizational networks that have formed or are forming within and across the collaborating clusters.

The ScanBalt central leadership promotes a variety of activities. For instance, it has initiated thematic networks to nurture collaboration within, for example, clinical research, marine biotechnology, or stem cell research. It has fostered shared SME services between clusters and public/private collaboration in the field of biosystems technologies. The ScanBalt Academy has been implemented to act as an external advisory and ambassador's body. ScanBalt exerts socio-political influence by publishing opinion papers, for example, focusing on stem cell research, and helps to create public awareness for the biotechnology sector in the partner regions and social acceptance for sometimes contested research projects. Since 2004, there have been approx. 1,700 mentions in the press. ScanBalt members also initiated the ScanBalt Health Region. It became a flagship project in the EU Baltic Sea Region Strategy and modeled its governance structure on ScanBalt's bottom-up approach, which insists that most of the work needs to be done in concrete projects in the regions:

"There is only a very small baseline funding, and it should stay like this. It is the only way you can have a sustainable organization, because making money across borders is not easy.” (ScanBalt interview)

On the decentralized level, different actors act as brokers at different points in time. One such actor is the biotechnology park at the University of Tartu in Estonia, which has been conducting the Estonian Genome Project since 2001 and has taken a leading role within ScanBalt. Generally, for each project idea a lead organization needs to be identified that is also willing to invest resources up-front and to oversee the project application and coordination.

In a similar way to ACOD, whose "state initiatives have emerged for different reasons and act under different conditions” (ACOD interview), ScanBalt stresses that the macroregional cooperation should not try to remove competition between regions because each has 
specific technological or research-based competences. The idea is rather to connect central regions, such as the Medicon Valley in the medical technology sector, and smaller, more peripheral regions in an “added-value macro-regional chain” (ScanBalt interview):

"(...) any region has some kind of competence to drive collaboration. This is very important because otherwise it would just be a matter of the capital regions taking their lead." (ScanBalt interview)

Accordingly, ScanBalt rarely holds its general assemblies in the capital cities, but in smaller cities and peripheral regions.

ScanBalt, like ACOD, has a highly formalized governance structure. It has taken several years of negotiation to agree on a set of formal statutes, but now these statutes are not questioned:

"It was not easy to establish the statutes. It took years of discussion about what should be the role of ScanBalt itself, how much direct power should it have, how much will the regions have, who are the most important universities, or companies, or clusters, etc. (...) it was very good that we spent all this time because today there are no serious discussions about it." (ScanBalt interview)

Over time, ScanBalt has developed a differentiated membership structure and now includes individual members as well as regions. Different rights and fees are attached to each membership status. It has adopted this structure so that ScanBalt can avoid "stealing" members from its member clusters, where most organizations already pay membership fees:

"The backbone of the ScanBalt BioRegion is the regional cluster organizations. They are themselves member-based associations and most do not have strong financing. ScanBalt should never ever compete against its own members. So therefore we say, those who are members of regional clusters are per definition also members of ScanBalt. We should not compete against a regional cluster.” (ScanBalt interview)

It is hereby necessary to distinguish administrative funding for organizing cluster networks from operational level funding, which is tied to projects and comes, for example, from specific EU or national programs or from firms interested in their outcomes.

The Tri-Cluster Alliance and Germany goes 3D have informal governance structures. In $3 \mathrm{D}$, the only formal document is a one-page joint vision paper, but the collaboration has formal selection criteria due to several membership requests. These criteria - each 
participating region must have an internationally renowned cluster in the music industry and host an internationally relevant industry event - are communicated through press interviews or interpersonally. 3D has considered becoming an independent legal entity, but has decided to delay this step until it becomes necessary, for example, because of joint funding applications. The participants fear that formal guidelines and requirements would put their personal relationships at risk:

"It is still guerilla-like. (...) Everything works on a voluntary basis. (...) Formal statutes could put our good personal relationships at risk, because once we have formal statutes, we would have to be stricter with each other.” (3D interview)

The Tri-Cluster Alliance is also based on verbal agreements between representatives of the Berlin, Tucson and Ottawa photonics clusters. There are no formal structures or dedicated resources for coordination and control. Relations within this collaboration are rather loose and sporadic:

"It is more an agreement by handshake. We have no contract. We (representatives of the regional network of optical technologies and the WISTA technology park in Berlin) sent an official letter of intention to Tucson, and that was it.” (Tri-Cluster interview)

Germany goes 3D is currently paid for directly by its three cluster representative organizations, as its current goals do not require intense project funding. The Tri-Cluster Alliance also lacks dedicated inter-cluster financing, with activities being financed out of the internationalization budgets of the clusters' administrative offices or the technology parks.

Not even the name Tri-Cluster Alliance has been established officially, since our interview partners also sometimes speak of the Tri-City Breakfast or the Tri-Region Alliance. It is often equated with the Global Advantage Network, an international networking program of the University of Arizona that was meant to grow out of the three clusters' collaboration and reach out to additional partners, but for which funding had been cut.

Both cases have not specified a central lead organization. While the Cologne cluster views itself as the main initiator of 3D, all interviewees stressed how informal and friendly relations as well as the current scope of activities have made it unnecessary to specify a 
formal lead organization and governance is currently shared. In the Tri-Cluster Alliance, informal leadership moved from the regional development office in Tucson to the international office of WISTA management GmbH, manager of the Berlin Adlershof science and technology park, when budgets were cut in the U.S. The Tri-Cluster Alliance thus has changing and informal internal lead organizations.

\subsubsection{Contingency Factors}

In each case there are both shared and partly diverging goals. Germany goes 3D and the TriCluster Alliance aim to gain visibility and increase political leverage, but their cluster representatives stress that they are not directly mandated by their member organizations but rather pursue these goals in their role as cluster managers. Despite being in very different industries, the main activities of these two cluster networks revolve around organizing joint trade fair representations and pooling resources for communicating the special competences of the participating clusters in their respective industry context to policy makers and potential customers. As a Tri-Cluster representative stated with reference to the often overlooked strategic importance of the photonics industry for other industries:

"There are too few of us and (...) we don't really compete against each other, we complement each other. (...) The value of what we invent and create needs to be propagated better.” (TriCluster interview)

Similarly, Germany goes 3D focuses on developing a common voice and sharing financial burdens:

"We are competitors, but we also maintain an open dialogue with each other. Our primary target is to develop greater bargaining power towards the outside, to become foreign ministers for music, so to speak.” (Germany goes 3D interview)

Trust is based on the intensity and duration of collaboration. The youngest cluster network is Germany goes 3D, which started only in 2010. Nonetheless, the collaborating partners refer to the high level of trust on the inter-cluster level, based on having known each other personally for several years from meeting at different music events. This perception of trust allows for shared participant governance, but is highly person-dependent. Germany goes 3D 
is furthermore embedded in numerous inter-organizational and inter-personal relations between the three music regions that are not directly brokered by 3D.

The Tri-Cluster Alliance has existed since 2004, but due to the geographic distance between the clusters there are only sporadic inter-cluster contacts, so that trust needs to be built and institutionalized. The network activity so far has consisted of mutual visits of cluster delegations and the regular cluster breakfast at the annual Photonics West industry exhibition and fair. These activities have increased the knowledge about the connected clusters' members and competences and have contributed to establishing loose ties, but a more central brokerage by leading business organizations and research institutes is considered necessary to extend the collaboration towards joint investments and projects:

"The cluster breakfast is a tradition by now. In the beginning it was a small circle. There you had the opportunity to really meet and chat and to become visible. It grew larger and larger. Now that we have seen the profiles, we need to reorganize to provide more focused content. Noncommittal meetings do not work anymore.” (Tri-Cluster interview)

In ACOD and ScanBalt, trust among inter-cluster actors but also increasingly among the organizations residing in the different clusters has developed over several years of intense collaboration. While ACOD is very active in establishing competence networks that comprise members from different state initiatives and work on themes such as aluminum or energyefficient production, collaboration targets at ScanBalt are auctioned via a number of EUfunded projects, indicating that ScanBalt has developed skills and routines in raising public funds for specific projects:

"One thing that has been very important over the years is that we are now a group of people who really know each other very well and have been with each other in various projects, and who can distribute their projects to the right partners. So we have established a kind of trust over these years and I think this is really a very valuable capital, which is extremely important.” (ScanBalt interview)

In terms of size, ScanBalt is the largest collaboration in our sample with 13 connected clusters and over 50 formal members, followed by ACOD with 5 participating state initiatives and about 370 organizations. Since these two initiatives decidedly reach out to project-based 
collaboration among the clusters' member organizations, intense brokerage is needed both on an inter-cluster level and below.

Regarding the nature of the task, Germany goes 3D has not tried so far to extend its current activities towards, for example, a joint funding application. The Tri-Cluster Alliance has attempted to broker exchanges among the different organizations within the connected clusters as well. Aiming to attract international subsidiaries from partner clusters, for instance, an exclusive business welcome package provided by the local business and technology parks for photonics companies from other clusters has been developed. Twice, a rotating international photonics summer school has been held in Berlin. It is currently unclear whether one of the Tri-Cluster partners will take a lead in pursuing these activities further, as goals and needs diverge to some extent. Attracting international subsidiaries, for instance, has mainly been a goal for the Berlin cluster historically lacking large photonics firms, but this goal has not been reached. The main aim for Tuscon was to gain knowledge about and establish contacts to suppliers, so that special orders could be handled quickly and this goal has been reached by the efforts so far. While Germany goes 3D continues its joint meetings and public relations, representatives of the Tri-Cluster Alliance thus describe the cooperation as increasingly dormant:

“The thread may be thin but the communication line is still there.” (Tri-Cluster interview) Goals also diverge within ScanBalt, limiting the extent of activities pursued on the intercluster level. For instance, ScanBalt tried to set up a Nordic Baltic Expat Platform on which members would share information about expatriates so that they could be attracted back to the ScanBalt regions. This project, like some other pilot projects, had to be stopped due to the members' unwillingness to share crucial information. Nonetheless, in both ACOD and ScanBalt goals are aligned by a joint interest in gaining national or EU funds for projects not a debated option for the intercontinental Tri-Cluster Alliance. The need for cluster and 
inter-cluster level competences is highest in ACOD and ScanBalt, because both initiatives require significant degrees of interdependence among partners on the inter-cluster level and among the organizations residing with the clusters in order to steer and conduct joint projects and coordinate activities on and across different levels in line with their goals.

\section{Discussion}

We identify two forms of cluster networks based on the differential emphases put on goals, governance approaches, and contingencies (Figure 1).

--- Insert Figure 1 about here ---

Germany goes 3D and the Tri-Cluster Alliance are examples of internally governed cluster networks. Cluster managers from CAOs or hub firms acting as cluster leaders deliberately establish relations with the partnering clusters' representatives. In both cases, the connected clusters aim to increase their visibility towards policy makers and to distribute and find information or potential partners in the other clusters. Collaborative ties between organizations residing in the different clusters may exist or emerge, but are not intensely brokered from the inter-cluster level, although jointly organized institutionalized events provide opportunities for actors on lower levels to detect new business opportunities and extend, for example, their knowledge about technologies or funding opportunities. Governance is informal in both cases, although both refer to an official letter of intent that indicates the existence of some formal rules.

ScanBalt and ACOD are examples of externally governed cluster networks, characterized by interactions both on inter-cluster and inter-organizational levels, while involving vertical linkages across these two levels. Ties in and between the connected clusters are brokered by institutionalized, cross-cluster governance structures on different levels in the form of an inter-cluster lead organization external to the clusters and several, 
sometimes changing, decentralized internal lead organizations. Whereas the central body is responsible for administering funds, creating, for instance, external visibility, and brokering lower-level ties to some extent, decentralized lead organizations are responsible for exploring project ideas, developing funding proposals, and implementing permanent or temporary collaborative cross-cluster structures.

Our findings show that internally governed cluster networks result when the crosscluster activities remain sporadic and do not require intense ties on lower levels. Although the Tri-Cluster Alliance and Germany goes 3D differ substantially regarding their regional scope and industry, they are comparable in their goals and the nature of the tasks pursued, such as the sharing of limited resources and gaining political visibility, and in the resulting low need for cluster and inter-cluster level competences. Leadership in these constellations can be shared or centralized, depending on the intensity of interaction between participants on and across levels, and on goal consensus. Internally governed cluster networks differ from organization-based linkages across clusters in the form of global pipelines (Lorenzen and Mudambi, 2012) in that lead organizations need not be flagship firms or MNEs, but can embrace small and medium enterprises or CAOs acting on behalf of clusters precisely because global pipelines are absent. The Tri-Cluster case also shows that cluster networks can potentially be terminated, although cluster connectivity may continue in the form of interpersonal or inter-organizational ties.

Externally governed cluster networks are established when the goal of the collaboration is to create intense "interlocking" among clusters in a wider geographical context (Asheim and Coenen, 2006). Their governance structures are implemented to develop co-specialized supply chains and increase the innovative capacity of often small and mediumsized suppliers (Smith et al., 2002) within a bounded environment. In our sample, externally governed cluster networks were established in neighboring regions, although these were not 
necessarily nationally bound. Externally governed cluster networks can thus be studied as a form of territorial innovation system (Moulaert and Sekia, 2003; Simmie, 2005) and enrich this stream of research, which is sometimes critiqued for neglecting actors and institutions outside of national boundaries (Cooke, 2005). They can also be understood as an intermediate structure between localized industrial clusters and global production networks (Rutherford and Holmes, 2008).

Our study applies the network governance framework (Provan and Kenis, 2008) to the study of clusters and inter-cluster linkages, but adds levels of analysis on which linkages may be formed. Lead organizations on the cluster level are either CAOs or hub firms acting on behalf of clusters. They may share governance on the inter-cluster level, or one cluster's representative organization may act as an internal lead organization. Centralized external governance is provided by inter-CAOs and often complemented by several decentralized brokers. Whether governance is shared depends in part on the nature of the clusters themselves. The music clusters, for instance, are all characterized by rather informal network structures, which characterize the cluster network as well (cf. Lorenzen and Mudambi, 2012). Furthermore, our findings indicate that strong and more powerful clusters tend to play a more central role in cluster networks. When budgets were cut in the Arizona photonics cluster, for instance, the Berlin cluster took on the leadership role in the Tri-Cluster Alliance. Governance tends to be less formalized when fostering regional development and raising public funds for the cluster network and for specific projects are of minor importance.

The findings reveal that different combinations of contingencies can lead to the same governance form. The comparison of ACOD and ScanBalt shows that both cases of externally governed cluster networks rely on similar approaches to leadership, brokerage, and formalization, and the extent of trust. They both coordinate relatively high numbers of participants. However, the cases differ regarding their regional scopes, goals, and cluster- and 
inter-cluster level competencies. They are engaged in different industries and pursue different tasks. The comparison of Germany goes 3D and the Tri-Cluster Alliance shows that these cases of internally governed cluster networks are also similar concerning leadership, brokerage, formalization, and the number of participants. They further resemble each other with respect to the tasks that they pursue and the intensity of collaboration. However, they differ referring to their goals, regional scopes, and industries. Thus, the decisive factors for the choice of a particular governance approach are similarities in leadership, brokerage, and formalization, as well as trust and the number of participants.

The network governance lens illustrates that structures for brokerage and leadership exist on the cluster and inter-cluster levels to ensure that resource exchanges are goaloriented and help all participants to reap joint and individual benefits (Provan and Kenis, 2008). Our findings add to our limited knowledge regarding the effectiveness of cluster networks (Mudambi and Swift, 2012). ScanBalt has been successful in gaining visibility and fostering knowledge transfer between the connected clusters and their member organizations. The amount of project-related funding and the increasingly tight connections to Brussels corroborate this point. Single actors (e.g. research institutes) benefit from the collaboration by getting access to knowledge held in other clusters, which they could not have obtained otherwise. ACOD increases its members' technological added value by jointly developing knowledge in special areas of expertise and opening up business opportunities that they would not get otherwise. Germany goes 3D has raised public interest in politically motivated endeavors to restructure the German music industry, fostering the external legitimacy of the existence of several decentralized clusters instead of a spatially concentrated allocation of organizations in the German capital. The Tri-Cluster Alliance has established knowledge about the connected clusters' competences but has failed to expand its activities. Based on our data, we cannot measure the effect of cluster networks on organization-level 
performance. Due to the existence of cross-cluster ties in many different industries, their multi-level character and complexity, and the lack of established measures (Mudambi and Swift, 2012; Provan and Kenis, 2008), a promising area for future research would be the development of new, possibly industry-specific and multi-dimensional measures of the outcomes of cross-cluster linkages.

A limitation of our study is its cross-sectional character. Changing contingency factors may lead from loosely coupled clusters to institutionalized, integrated cluster networks or - as indicated by the Tri-Cluster case - vice versa, while participants' increasing collaboration experience may foster a dynamic evolution in their governance on various levels (Powell et al., 2005; Ter Wal and Boschma, 2011). Further research could include, for example, identity (Romanelli and Khessina, 2005) or power relations (Christopherson and Clark, 2007) as additional contingency factors. We do not claim that our forms of cluster networks are exhaustive, but a governance lens provides an important addition to our current knowledge on cluster connectivity, which should stimulate further research on this phenomenon. 


\section{References}

Asheim, B. T. and Coenen, L. (2005) Knowledge bases and regional innovation systems: Comparing Nordic clusters, Research Policy, 34, pp. 1173-1190.

Asheim, B. T. and Coenen, L. (2006) Contextualising regional innovation systems in a globalising learning economy: On knowledge bases and institutional frameworks, Journal of Technology Transfer, 31, pp. 163-173.

Asheim, B.T. and Isaksen, A. (2002) Regional innovation systems: the integration of local 'sticky' and global 'ubiquitous' knowledge, Journal of Technology Transfer, 27, pp. 77-86.

Bathelt, H., Malmberg, A. and Maskell, P. (2004) Clusters and knowledge: local buzz, global pipelines and the process of knowledge creation, Progress in Human Geography, 28(1), pp. 31-56.

Boschma, R. (2005) Proximity and innovation: a critical assessment. Regional Studies, 39, pp. 61-74

Bresnahan, T., Gambardella, A. and Saxenian, A. (2001) 'Old economy' inputs for 'new economy' outcomes: cluster formation in the new Silicon Valleys, Industrial and Corporate Change, 10(4), pp. 835-860.

Bunker Whittington, K., Owen-Smith, J. and Powell, W. W. (2009) Networks, propinquity, and innovation in knowledge-intensive industries, Administrative Science Quarterly, 54, pp. 90-122.

Burt, R. S. (1992) Structural Holes: The Social Structure of Competition (Cambridge, MA, London: Harvard University Press).

Cheung, M.-S., Myers, M. B. and Mentzer, J. T. (2011) The value of relational learning in global buyer-supplier exchanges: A dyadic perspective and test of the pie-sharing premise, Strategic Management Journal, 32, pp. 1061-1082.

Cooke, P. (2005) Regionally asymmetric knowledge capabilities and open innovation: Exploring 'Globalisation 2' - a new model of industry organization, Research Policy, 34(8), pp. 1128-1149.

Christopherson, S. and Clark, J. (2007). Power in firm networks: what it means for dynamic regional innovation systems. Regional Studies, 41, 1223-1236.

Dohse, D. (2000) Technology policy and the regions - the case of the BioRegio contest, Research Policy, 29 (9), pp. 1111-1133.

Dohse, D. (2007) Cluster-based technology policy - the German experience, Industry and Innovation, 14(1), pp. 69-94.

Engel, J. S. and del-Palacio, I. (2011) Global clusters of innovation: The case of Israel and Silicon Valley, California Management Review, 53(2), pp. 27-49.

Giblin, M. (2011) Managing the global-local dimensions of clusters and the role of "lead" organizations: The contrasting cases of the software and medical technology clusters in the west of Ireland, European Planning Studies, 19(1), pp. 23-42.

Gilding, M. (2008) 'The tyranny of distance': Biotechnology networks and clusters in the antipodes, Research Policy, 37, pp. 1132-1144.

Granovetter, M. (1973) The strength of weak ties, American Journal of Sociology, 78, pp. 
1360-1380.

Gupta, A. K. and Govindarajan, V. (2000) Managing global expansion: A conceptual framework, Business Horizons, 43(2), pp. 45-54.

He, J. and Fallah, H. (2011) The typology of technology clusters and its evolution - evidence from the hi-tech industries, Technological Forecasting and Social Change, 78 (6), pp. 945-952.

Henn, S. (2012) Transnational entrepreneurs, global pipelines and shifting production patterns. The example of the Palanpuris in the diamond sector, Geoforum, 43, pp. 497506.

Herrmann, A. M., Taks, J. L. and Moors, E. (2012) Beyond regional clusters: On the importance of geographical proximity for R\&D collaborations in a global economy the case of the Flemish Biotech sector, Industry and Innovation, 19(6), pp. 499-516.

Hoover, E. (1937) Location Theory and the Shoe and Leather Industries (Cambridge, MA: Harvard University Press).

Human, S. E. and Provan, K. G. (2000) Legitimacy building in the evolution of small-firm multilateral networks: A comparative study of success and demise, Administrative Science Quarterly, 45(2), pp. 327-365.

Humphrey, J. and Schmitz, H. (2002) How does insertion in global value chains affect upgrading in industrial clusters? Regional Studies, 36, pp. 1017-27.

Huxham, C. and Vangen, S. (2000) Leadership in the shaping and implementation of collaboration agendas: How things happen in a (not quite) joined up world, Academy of Management Journal, 43, pp. 1159-1175.

Huxham, C. and Vangen, S. (2005) Managing to Collaborate (London: Sage).

Jarillo, J. C. (1988) On strategic networks, Strategic Management Journal, 9(1), pp. 31-41.

Kenis, P. and Provan, K. G. (2006) The control of public networks, International Public Management Journal, 9(3), pp. 227-247.

Kilduff, M. and Tsai, W. (2003) Social networks and organization (London: Sage).

Kuhlmann, S. and Edler, J. (2003) Scenarios of technology and innovation policies in Europe: Investigating future governance, Technological Forecasting and Social Change, 70, pp. 619-637.

Lorenzen, M. and Mudambi, R. (2012) Clusters, connectivity and catch-up: Bollywood and Bangalore in the global economy, Journal of Economic Geography, DOI: 10.1093/jeg/lbs017.

Marshall, A. (1890) Principles of Economics: An Introductory Volume (London: Macmillan).

Martin, R. and Sunley, P. (2003) Deconstructing clusters: chaotic concept or policy panacea? Economic Geography, 3, pp. 5-35.

Maskell, P., Bathelt, H. and Malmberg, A. (2006) Building global knowledge pipelines: The role of temporary clusters, European Planning Studies, 14(8), pp. 997-1013.

Menzel, M.-P. and Fornahl, D. (2010) Cluster life cycles - dimensions and rationales of cluster evolution, Industrial and Corporate Change, 19(1), pp. 205-238.

Moulaert, F. and Sekia, F. (2003) Territorial innovation systems: a critical survey, Regional Studies, 37(3), pp. 289-302. 
Mudambi, R. and Swift, T. (2012) Multinational enterprises and the geographical clustering of innovation, Industry and Innovation, 19(1), pp. 1-21.

Pavitt, K. (1984) Sectoral patterns of technical change: Towards a taxonomy and a theory, Research Policy, 13, pp. 343-373.

Porter, M. E. (1998) On Competition (Boston, MA: Harvard Business School Publishing).

Powell, W. W., White, D. R., Koput, K. W. and Owen-Smith, J. (2005) Network dynamics and field evolution: The growth of interorganizational collaboration in the life sciences, American Journal of Sociology, 110(4), pp. 1132-1205.

Provan, K. G. and Kenis, P. (2008) Modes of network governance: Structure, management, and effectiveness, Journal of Public Administration Research and Theory, 18, pp. 229252.

Provan, K. G., Fish, A., and Sydow, J. (2007) Interorganizational networks at the network level: A review of the empirical literature on whole networks, Journal of Management, 33, pp. 479-516.

Romanelli, E. and Khessina, O. M. (2005) Regional industrial identity: Cluster configurations and economic development, Organization Science, 16(4), pp. 344-358.

Rutherford, T. D. and Holmes, J. (2008). 'The flea on the tail of the dog': power in global production networks and the restructuring of Canadian automotive clusters. Journal of Economic Geography, 8, 519-544.

Rychen, F. and Zimmermann, J.-B. (2008) Clusters in the Global Knowledge-Based Economy: Knowledge Gatekeepers and Temporary Proximity, Regional Studies, 42(6), pp. 767-776.

Saxenian, A. (2002) Transnational communities and the evolution of global production networks: The cases of Taiwan, China and India, Industry and Innovation, 9(3), pp. 183-202.

Saxenian, A. (2006) The New Argonauts. Regional Advantage in a Global Economy (Cambridge: Harvard University Press).

Saxenian, A. and Hsu, J.-Y. (2001) The Silicon Valley-Hsinchu connection: Technical communities and industrial upgrading, Industrial and Corporate Change, 10 (4), pp. 893-920.

Scott, A. J. (2002) A new map of Hollywood: The production and distribution of American motion pictures, Regional Studies, 36, pp. 957-975.

Simmie, J. (2005) Innovation and space: a critical review of the literature, Regional Studies, 39(6), pp. 789-804.

Smith, A., Rainnie, A., Dunford, M., Hardy, J., Hudson, R., and Sadler, D. (2002). Networks of value, commodities and regions: reworking divisions of labour in macro-regional economies, Progress in Human Geography, 26, 41-63.

Staber, U. (1997) Specialization in a declining industrial district: The case of BadenWürttemberg textiles and clothing, Growth and Change, 28(49), pp. 475-495.

Sydow, J., Lerch, F., Huxham, C. and Hibbert, P. (2011) A silent cry for leadership: Organizing for leading (in) clusters, Leadership Quarterly, 22(2), pp. 328-343.

Ter Wal, A. L. J. and Boschma, R. (2011) Co-evolution of firms, industries and networks in space, Regional Studies, 45 (7), pp. 919-933. 
Vapola, T. J. (2011) The laws of attraction: What attracts innovative start-up firms to partnerships with global MNCs? Journal of International Entrepreneurship, 9, pp. 3961.

Visser, E.-J. (2009) The complementary dynamic effects of clusters and networks, Industry and Innovation, 16(2), pp. 167-195.

Visser, E.-J. and Atzema, O. (2008) With or without clusters: Facilitating innovation through a differentiated and combined network approach, European Planning Studies, 16(9), pp. 1169-1188.

Visser, E.-J. and Boschma, R. (2004) Learning in districts: Novelty and lock-in in a regional context, European Planning Studies, 12(6), pp. 793-808.

Yin, R. K. (2009) Case Study Research: Design and Methods (Thousand Oaks: Sage). 
"This is an Accepted Manuscript of an article published by Taylor \& Francis in Industry and Innovation on 26 Jun 2013, available at http://www.tandfonline.com/10.1080/13662716.2013.805929" 